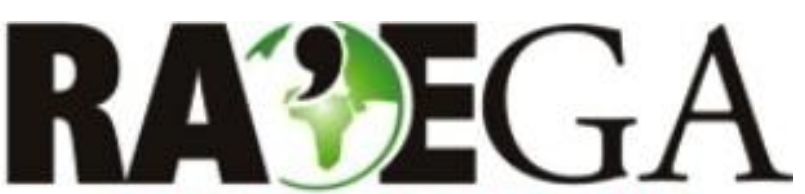

O ESPACYO GEOGRAFICO EM ANÁLISE

\title{
INTEGRAÇÃO TERRITORIAL DO LITORAL DO ESTADO DO PARANÁ (BRASIL): TRANSPORTES, BALNEARIZAÇÃO E PATRIMONIALIZAÇÃO NA FORMAÇÃO E DINÂMICA DO ESPAÇO TURÍSTICO
}

\section{TERRITORIAL INTEGRATION OF THE COAST OF PARANÁ STATE (BRAZIL): TRANSPORT, RESORT DEVELOPMENT AND PATRIMONIALIZATION IN THE FORMATION AND DYNAMICS OF TOURIST SPACES}

\author{
Marcelo Chemin \\ Professor da Universidade Federal do Paraná (UFPR) \\ Setor Litoral \\ Matinhos, PR \\ e-mail:marcelochemin@ufpr.br \\ Cinthia Maria de Sena Abrahão \\ Professor da Universidade Federal do Paraná (UFPR) \\ Setor Litoral \\ Matinhos, $P R$ \\ e-mail: cisena@terra.com.br
}

Recebido em: 18/08/2013

\section{Resumo}

Este artigo resulta de uma pesquisa que objetiva conhecer e evidenciar as dinâmicas e as configurações do fenômeno turístico no litoral paranaense. A primeira parte contextualiza o desenvolvimento dos recursos de infraestrutura de transportes e a integração geográfica do litoral com o território paranaense e Sul brasileiro. Em seguida o estudo relaciona esta contextualização inicial com a configuração de espaços turísticos da região, mediante articulação com outros dois processos: balnearização e patrimonialização. Trata-se de uma leitura da dimensão espacial do turismo realizada pari passu à contextualização histórica e regional da formação desse território. Basearam a investigação pesquisas bibliográficas e documentais (fontes estatísticas, mapas, fotografias e base de dados institucionais). Também foram realizadas saídas de campo que viabilizaram conferência de dados, coleta de informações e melhor entendimento geográfico dos caminhos ferroviários e rodoviários. Ao reconstruir as vinculações entre o processo de integração territorial do Paraná, particularmente, no que se refere às conexões entre litoral e o interior do estado, foram sendo elucidadas as condições materiais para os fluxos de deslocamento que, desde os anos 1920, permitiram a constituição dos espaços 
INTEGRAÇÃO TERRITORIAL DO LITORAL DO ESTADO DO PARANÁ (BRASIL): TRANSPORTES, BALNEARIZAÇÃO E PATRIMONIALIZAÇÃO NA FORMAÇÃO E DINÂMICA DO ESPAÇO TURÍSTICO

turísticos. De forma geral, os diversos elementos históricos que colaboraram para configurar a região possibilitaram a consolidação tanto dos processos de balnearização, como de patrimonialização. Ambos se apresentam como expressões fundamentais do turismo e da própria caracterização da região, no que tange ao fenômeno turístico.

Palavras-chave: espaços turísticos, transportes, balnearização, patrimonialização, litoral do Paraná.

\begin{abstract}
This article is the result of research that aims to understand and demonstrate the dynamics and configurations of the tourism phenomenon on the coast of Paraná. The first part contextualizes the development of resources for the transport infrastructure and the geographical integration of the coastal region with the rest of Paraná and southern Brazil. This initial contextualization is then related to the configuration of tourist areas in the region by linking it with two other processes: resort development and patrimonialization. This is a reading of the spatial dimension of tourism, which is presented hand-in-hand with an historical and regional contextualization of the development of this territory. It is based on literature searches and documentary research (statistical sources, maps, photographs and institutional databases). Field trips were also conducted that enabled data conferencing, data collection and a better geographical understanding of railways and roads. By reconstructing the links between the process of territorial integration of Paraná, particularly with regard to the connections between the coast and the interior of the state, the material conditions for the flows of displacement since the 1920s, which led to the establishment of tourist spaces, are made clear. Overall, the diversity of historical elements that contributed to set up the region, enabled the consolidation of both processes of resort development and patrimonialization. Both reveal themselves as fundamental expressions of tourism and the characterization of the region, regarding the tourism phenomenon.
\end{abstract}

Keywords: tourist spaces, transport, resort development, patrimonialization, Paraná coast.

\title{
INTRODUÇÃO
}

O estabelecimento de vias de acesso e de comunicação recebe atenção frequente em estudos sobre formação histórica de territórios devido ao incentivo que exercem na fundação de povoados, cidades e instalação de processos produtivos. No Litoral do Estado do Paraná, Sul do Brasil, rotas e caminhos rudimentares (terrestres e aquaviários) favoreceram o conhecimento europeu desse antigo território indígena desde o século XVI. No curso do tempo, o escoamento da matéria 
INTEGRAÇÃO TERRITORIAL DO LITORAL DO ESTADO DO PARANÁ (BRASIL): TRANSPORTES, BALNEARIZAÇÃO E PATRIMONIALIZAÇÃO NA FORMAÇÃO E DINÂMICA DO ESPAÇO TURÍSTICO

prima que transitava pelos caminhos do "Paraná Tradicional" através dos portos (Antonina e Paranaguá) alavancou a constituição histórica de vias de acesso e a modernização do sistema de transportes na região.

Neste artigo, em primeiro momento, este processo é contextualizado a partir dos recursos de infraestrutura de transportes que viabilizaram a integração geográfica do litoral com o território paranaense e Sul brasileiro, para posteriormente apresentar uma interpretação de sua contribuição na configuração de espaços turísticos da região, mediante articulação com outros dois processos: balnearização e patrimonialização.

Trabalha-se espaço turístico na perspectiva conceitual de Lozato-Giotard (1990), autor que enfatiza a distribuição geográfica de atrativos como o elemento fundamental, mas considera também os fluxos de frequentação, as interações entre o turismo e as diferentes atividades que definem o uso e a ocupação do solo e, ainda, o conjunto de instalações que conferem suporte às práticas turísticas.

Isto posto, o texto sintetiza resultados parciais da pesquisa "Dinâmicas e configurações do turismo no litoral do Paraná"2. Trata-se de uma leitura espacial do turismo realizada pari passu à contextualização histórica e regional da formação desse território. $\mathrm{O}$ estudo demandou pesquisas bibliográficas e documentais (fontes estatísticas, mapas, fotografias e base de dados institucionais). De modo complementar, saídas de campo ${ }^{3}$ viabilizaram conferência de dados, informações e melhor entendimento geográfico dos caminhos ferroviários e rodoviários.

Será demonstrado cronologicamente como a constituição de vias de acesso e de meios de transporte participaram da complexificação desse território, uma vez que possibilitaram, entre outras dinâmicas instaladas, integração e mobilidade de fluxos. Acompanhando esse movimento crescente de relações do litoral com outras

\footnotetext{
${ }^{1}$ O que se convencionou nomear "Paraná Tradicional" correspondea porção territorial composta pelo litoral, primeiro planalto, Campos Gerais, Campos de Guarapuava e Palmas.

2 Desenvolvida na Universidade Federal do Paraná (Setor Litoral), registro BANPESQ 2012003470, ID 3470.

${ }^{3}$ Uma das etapas da pesquisa constituiu no reconhecimento in loco de localidades e equipamentos citados na bibliografia consultada como marcos relevantes da história regional dos sistemas de transportes, tais como: Matinhos (Colônias da Estrada Alexandra- Matinhos); Distrito e Estrada Velha de Alexandra (Paranaguá); Morretes e Antonina (Ferrovia e estações, Rodovias PR 340, 408, 410, $411,804)$.
} 

INTEGRAÇÃO TERRITORIAL DO LITORAL DO ESTADO DO PARANÁ (BRASIL): TRANSPORTES, BALNEARIZAÇÃO
E PATRIMONIALIZAÇÃO NA FORMAÇÃO E DINÂMICA DO ESPAÇO TURÍSTICO

regiões, na década de $1920^{4}$, iniciou-se a produção de espaços associados ao turismo, como efeito do uso ${ }^{5}$ das praias da costa continental ao Sul da baía de Paranaguá.

O processo de balnearização propiciou que esta porção litorânea ingressasse no mapa paranaense como recanto e lócus de lazer, de encontro e vida social. Nas décadas seguintes, sobretudo na segunda metade do século $X X$, a dinâmica turística tornou-se mais intensa, a balnearização acelerou, assim como as ações de patrimonialização, que gradativamente proporcionaram uma fusão da imagem patrimonial da região com a imagem turística.

Após pouco mais de oito décadas dos movimentos embrionários do turismo local e dos efeitos dos processos de balnearização e patrimonialização, a região passou a ter seu território pontuado por uma diversidade de espaços turísticos, materializados junto a balneários marítimos, recantos fluviais, cidades históricas, territórios insulares e espaços naturais delimitados como unidades de conservação.

Intensificados nas funções de lazer e fruição social, os espaços turísticos deste litoral revelam a expressão local de uma dinâmica de escala transnacional, presente na realidade territorial de diversos países (PEARCE, 2003; URRY, 2001; VEGA, 1979; CLAVÉ, 1998 e 2009). Apresentam diferentes lógicas de criação, estruturas e funções instaladas; intensidade e características de frequentação turística; níveis de integração com outras atividades produtivas e de interferência no uso e na ocupação do solo. Os resultados aqui registrados contribuem para 0 conhecimento de elementos do processo de configuração desses espaços.

\footnotetext{
${ }^{4}$ Embora Cornelsen (2000) indique as excursões pioneiras para o Pico Marumbi na última década do século XIX como o início do turismo em áreas naturais no Paraná, o que marcaria então a própria origem das práticas de turismo neste litoral, as informações contidas em Alves (2008), sobre motivações e formas de organização de tais grupos, permitem um novo arranjo desta interpretação e seu deslocamento para a década de 1940. Mantêm com isso o entendimento de que são as práticas concernentes ao uso balneário que originam o turismo e definem seus primeiros espaços na região.

${ }^{5}$ A apropriação social da praia pelo uso balneário iniciou nas imediações do Morro de Caiobá e do Pico de Matinhos, ambos no atual município de Matinhos, conforme expõem Bigarella (2009) e Sampaio (2006). Na llha do Mel este tipo de uso era mais esporádico (ATHAYDE e BRITEZ, 2005), contudo também remete às décadas de 1920 e 1930.
} 
INTEGRAÇÃO TERRITORIAL DO LITORAL DO ESTADO DO PARANÁ (BRASIL): TRANSPORTES, BALNEARIZAÇÃO E PATRIMONIALIZAÇÃO NA FORMAÇÃO E DINÂMICA DO ESPAÇO TURÍSTICO

\section{CAMINHOS DA INTEGRAÇÃO TERRITORIAL E DOS TRANSPORTES NO LITORAL E NO PARANÁ}

A formação do Paraná teve na porção litorânea, antes território indígena, o primeiro núcleo de ocupação e poder. O processo de ocupação iniciado ainda no século XVI foi impulsionado pela exploração do ouro em rios da Baía de Paranaguá. $\mathrm{O}$ aspecto mais significativo deste processo, todavia, se deveu à ascensão da economia ervateira, grande geradora de riqueza no século XIX, e cujo escoamento se dava pelo Porto de Paranaguá (WACHOWICZ, 2001; FOGASSA, 2007; GODOY, 1998).

Até 0 início do século $X X \circ$ território paranaense esteve praticamente circunscrito ao "Paraná Tradicional". Em grande medida a constituição dele se baseou na rede de circulação composta por caminhos pré-coloniais ${ }^{6}$ e coloniais, sobrepondo-se gradativamente a ela, mediante diferentes rotas, hierarquias e preferências (STRAFORINI, 2007; COLAVITE, 2006).

A trama de caminhos indígenas viabilizou a penetração inicial do território, que posteriormente teve intensificada sua dinâmica por processos de ocupação e deslocamento de mercadorias por vias terrestres, algumas de maior dimensão e potencial de integração, como o Caminho Viamão (ou Caminho dos Tropeiros). Várias cidades se formaram ao longo deste. No Paraná, isto ocorreu especialmente nos Campos Gerais (p. ex. Lapa, Ponta Grossa, Castro, Piraí do Sul, Jaguariaíva), região que se estende ao longo do segundo planalto paranaense. Os povoamentos e cidades que compunham a rota entre Viamão e Sorocaba mantinham atividades de criação e comércio de animais (GIL, 2009; SILVA, 2005).

$O$ estudo do ciclo ervateiro ao longo do século XIX permite identificar importantes fatores que induziram transformações sócio espaciais no litoral e no interior paranaense por meio da circulação de produtos, mercadorias e estabelecimento de vias de acesso, meios de transportes e de comunicações que promoveram integração e novos ordenamentos territoriais (LEANDRO, 2003).

\footnotetext{
${ }^{6}$ O Caminho do Peabiru, por exemplo, que remonta ao período pré-colombiano, ligava as costas do Pacífico e do Atlântico na América do Sul. Integrava diversos territórios que atualmente compõem as regiões Sul, Sudeste e Centro-Oeste brasileiras, particularmente, São Paulo, Paraná e Santa Catarina. O Peabiru foi intensamente utilizado no período colonial, por padres jesuítas, aventureiros e comerciantes (STRAFORINI, 2007; COLAVITE, 2006).
} 
INTEGRAÇÃO TERRITORIAL DO LITORAL DO ESTADO DO PARANÁ (BRASIL): TRANSPORTES, BALNEARIZAÇÃO E PATRIMONIALIZAÇÃO NA FORMAÇÃO E DINÂMICA DO ESPAÇO TURÍSTICO

Desde o século XVIII os fluxos entre o planalto e o litoral eram intensos. Além da exportação da erva-mate, Curitiba participava das relações sul-americanas exportando, por meio do porto de Paranaguá, milho, feijão, trigo, tabaco, carne-seca e toucinho para Buenos Aires e Montevidéu. De outro modo, sal, algodão e farinha de trigo eram mercadorias que vinham da Praça de Paranaguá (KROETZ, 1985).

A cidade portuária de Paranaguá exerceu um papel fundamental nesses circuitos, todavia, Leandro (2003), ao analisar a origem da riqueza da província, afirma que a geração e retenção da riqueza não ocorreram em seus domínios. Em que pese a localização estratégica para escoamento via transporte marítimo, esta era desprovida de produção agrícola e de capacidade de apropriação dos resultados do comércio do 'ouro verde'. Entretanto, identificou-se que nela havia um pequeno grupo de comerciantes capitalizados, que conduziam o negócio ervateiro. Tratava-se de detentores de áreas de produção e beneficiamento em outras localidades (inicialmente no litoral, em Morretes e Porto de Cima, posteriormente, na região da Vila de Curitiba).

A autonomia política do Paraná ampliou o horizonte de investimentos que deram suporte e fortaleceram atividades econômicas, processo este vinculado aos projetos de infraestrutura do governo imperial que percebia a ligação Leste-Oeste, do Porto de Paranaguá com os sertões do Centro-Oeste da província do Paraná, como estratégica para a integridade territorial brasileira ${ }^{7}$ (KROETZ, 1985). Nesse contexto, o estabelecimento de Curitiba como capital, em 1853, redesenhou as relações comerciais e políticas, implicando em novos contornos territoriais, em função do desenvolvimento das porções interioranas do Paraná.

Scheiffer (2008) mostra que desde a definição da capital até 1935, ano em que foi inaugurado o porto D. Pedro II, Paranaguá perdeu o título de cidade mais importante da província. A consolidação de cidade portuária da província não foi suficiente para evitar certo declínio político, econômico, demográfico, e, sobretudo, cultural desta que havia se constituído como principal núcleo urbano do litoral.

\footnotetext{
${ }^{7}$ O comentário do Jornal 19 de Dezembro, publicado em 1875, sobre a construção da Ferrovia Curitiba-Paranaguá, expressa o caráter estratégico do projeto. Segundo o mesmo, a ferrovia deveria se estender para Oeste para possibilitar a criação de um laço entre o Brasil e seus vizinhos, mas também como forma eficiente para responder a qualquer ameaça bélica (WACHOWICKZ, 1994, p.87).
} 
INTEGRAÇÃO TERRITORIAL DO LITORAL DO ESTADO DO PARANÁ (BRASIL): TRANSPORTES, BALNEARIZAÇÃO
E PATRIMONIALIZAÇÃO NA FORMAÇÃO E DINÂMICA DO ESPAÇO TURÍSTICO

A construção da estrada da Graciosa deve ser vista como um fato diretamente vinculado à concretização da emancipação da província (1853), cujos gestores tinham clareza da necessidade de criar infraestrutura capaz de viabilizar a atividade extrativista de erva-mate e de madeira (WACHOWICZ, 1994; KROETZ, 1985). Possibilitou o deslocamento do beneficiamento da erva-mate, antes realizado nos engenhos de Porto de Cima e Morretes, para o planalto, mais especificamente para Curitiba (OLIVEIRA, 1974). Concluída em 1873, levou ambos os lugares a um período de decadência, como decorrência da exclusão da rota dos viajantes. Ao mesmo tempo, firmou Paranaguá como porto de escoamento do mate. De acordo com os dados de Linhares (1969), em 1826, cerca de $70 \%$ da expedição da ervamate para a região da Bacia do Rio da Prata partia deste porto.

Assim como a estrada da Graciosa, a Ferrovia representou outro elemento de significativa relevância para a integração territorial do Paraná. No último quartel do século XIX, a entrada do Paraná na era ferroviária foi mais um marco de integração entre litoral e o interior da província, particularmente, o primeiro planalto. Conforme Kroetz (1985, p. 41):

Sentindo necessidade premente de maior desenvolvimento nas atividades agrícolas, comerciais e industriais, os paranaenses elaboraram planos e metas ferroviárias, empolgados pelos seus vizinhos paulistas, que, já haviam unido os primeiros centros de produção do interior ao Porto de Santos.

A ferrovia viabilizou a expansão do negócio madeireiro no Paraná ${ }^{8}$. Isto foi uma decorrência da viabilização do transporte de madeira extraída do planalto paranaense no final do século XIX, direcionada às cidades do Rio de Janeiro e São Paulo que viviam acelerados processos de urbanização (LEANDRO, 1999). percurso definido ligava Paranaguá a Curitiba, dividido em três seções, ParanaguáMorretes $(42 \mathrm{Km})$, Morretes-Roça Nova $(38 \mathrm{Km})$ e Roça Nova-Curitiba $(30 \mathrm{Km})$. $\mathrm{O}$ isolamento de Antonina foi minimizado em função da construção de um ramal de

\footnotetext{
${ }^{8}$ Negócio que já era importante no litoral desde o início do século XIX, o que pode ser comprovado pelo registro realizado pelo botânico francês Auguste Saint-Hilaire, que indicou em seu diário que "as tábuas", conforme se referia ao produto, eram artigo de exportação destacável em Paranaguá e mesmo em Guaratuba (SAINT-HILAIRE, 1978). De forma geral, como indica Leandro (1999), seus registros apontam para a venda lucrativa de madeira que se destinava aos portos de Buenos Aires e Montevidéu.
} 
INTEGRAÇÃO TERRITORIAL DO LITORAL DO ESTADO DO PARANÁ (BRASIL): TRANSPORTES, BALNEARIZAÇÃO E PATRIMONIALIZAÇÃO NA FORMAÇÃO E DINÂMICA DO ESPAÇO TURÍSTICO

Morretes-Antonina $(16 \mathrm{Km})$, em 1887. A extensão da linha férrea de Curitiba até Ponta Grossa (185 Km), em 1892, e, o ramal de Rio Negro $(81 \mathrm{Km})$ e Porto Amazonas $(40 \mathrm{Km})$ completaram o processo de ligação da região, por meio desse modal (KROETZ, 1985).

A Figura 1, que traz um mapa histórico do Paraná de 1908, ilustra o contorno do estado antes da Guerra do Contestado e evidencia, mediante a concentração de cidades e vias de ligação entre elas, a porção territorial conhecida como Paraná Tradicional. No eixo Leste-Oeste destacam-se as ferrovias Paranaguá-Curitiba e Curitiba-Ponta Grossa, ao passo que no eixo Norte-sul, a integração entre os estados do Sul e São Paulo aparece concretizada pela Estrada de Ferro São PauloRio Grande.

Neste período muitas das relações econômicas da região Norte do Paraná estavam vinculadas ao estado de São Paulo. De modo semelhante, o Sudoeste/Oeste construiu vínculos mais fortes com o Rio Grande do Sul. Em contrapartida, a observação da Figura 1 destaca a concentração dos equipamentos de transporte no eixo Paranaguá-Curitiba. Tais aspectos levaram Vargas (2005) a apontar a evidência de um risco à hegemonia política da capital paranaense.

A estrutura viária do Paraná no período demonstrava dupla centralidade, com São Paulo e Curitiba no comando da base produtiva por intermédio da rede de transportes e comercialização. $O$ arranjo econômico decorrente da conjuntura do pós segunda guerra impulsionou a expansão da cultura cafeeira por novos territórios, especialmente na região Norte, que possuía aspectos bastante favoráveis a esta cultura, como solo, clima e, sobretudo, infraestrutura, com rota de escoamento atrelada a São Paulo, líder da cadeia de negócios de exportação (PADIS, 1981).

No mesmo período, a prioridade dada ao modal rodoviário, tanto no Paraná como em nível nacional, implicaram em marginalização das outras modalidades viárias (IPARDES, 1979), sobretudo o modal ferroviário. O que reverteu a tendência que havia no início do século $X X$, quando a expansão viária e integração territorial eram pensadas com essa base, também demonstrada na Figura 1. A insuficiência dos investimentos na malha ferroviária, desde os anos 1950, tanto em termos técnicos, como de traçado tornou-secada vez mais evidente. 
INTEGRAÇÃO TERRITORIAL DO LITORAL DO ESTADO DO PARANÁ (BRASIL): TRANSPORTES, BALNEARIZAÇÃO E PATRIMONIALIZAÇÃO NA FORMAÇÃO E DINÂMICA DO ESPAÇO TURÍSTICO

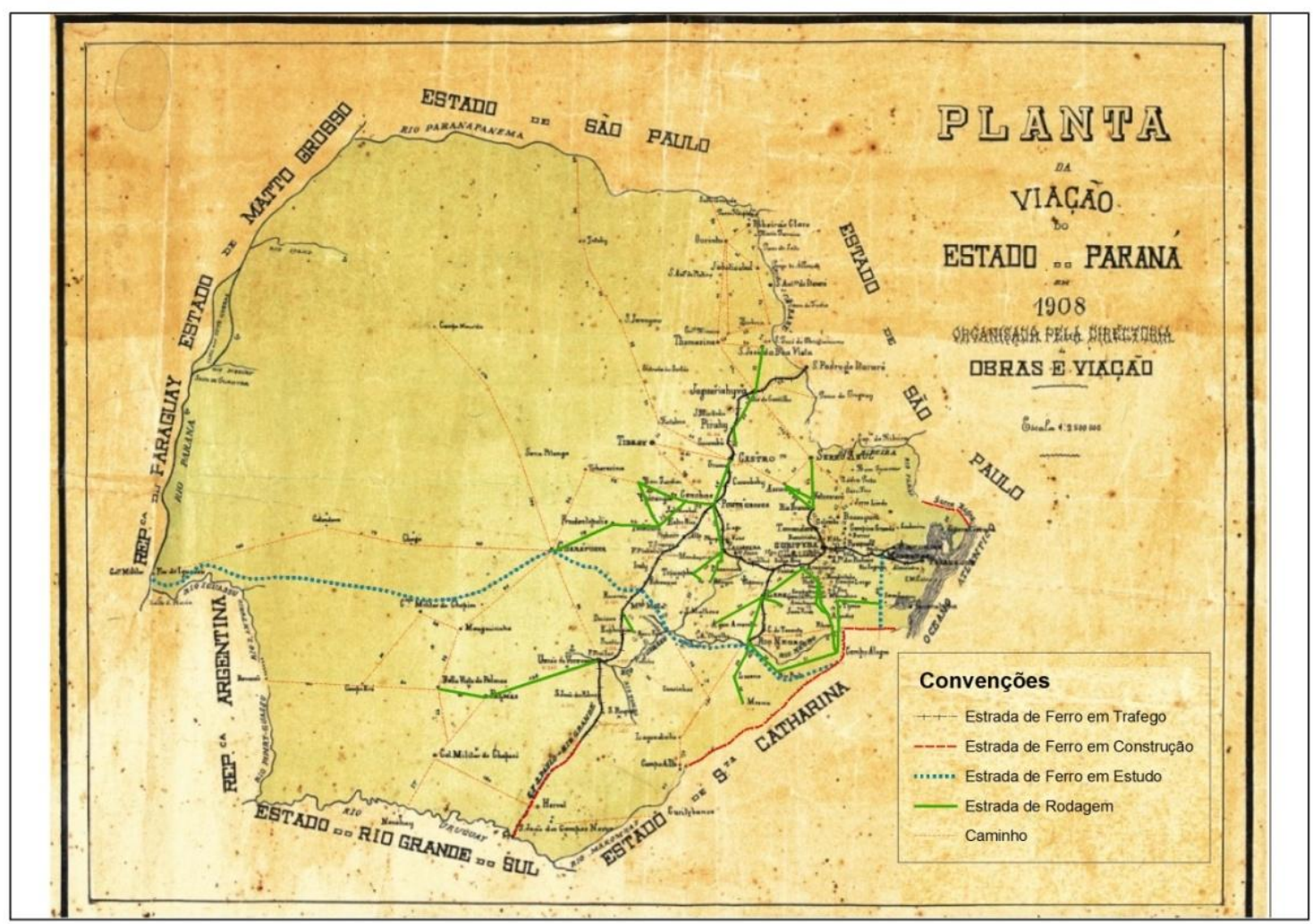

Figura 1: Estrutura viária do Paraná em 1908. Fonte: Instituto de Terras, Cartografia e Geociência. Fonte: Acervo Digital, disponível em: http//www.itcg.pr.gov.br

Vargas (2005) mostra, no caso paranaense, o papel da união de esforços entre as esferas de governo federal e estadual, para execução de ligações territoriais de grande expressão e também para consolidação de prioridades no modal rodoviário. A rodovia símbolo dos investimentos foi a BR376, conhecida como Rodovia do Café, eixo de integração Norte e Sul do estado, além de canal para intercâmbio da região com o sul do Mato Grosso ${ }^{9}$. Em geral, os interesses estavam direcionados para o fomento do mercado interno e efetivação de corredores de escoamento de produção para exportação pelos portos do estado, em especial pelo Porto de Paranaguá.

Em que pese a tônica rodoviarista dos investimentos em infraestrutura de transportes, no que tange ao modal ferroviário, consta que o Paraná foi um dos poucos estados brasileiros a expandir a malha ferroviária na segunda metade do século XX. A construção da Estrada de Ferro Central do Paraná permitiu ligação da

\footnotetext{
${ }^{9}$ No mesmo período foi construída a Estrada de Ferro "Central do Paraná".
} 
INTEGRAÇÃO TERRITORIAL DO LITORAL DO ESTADO DO PARANÁ (BRASIL): TRANSPORTES, BALNEARIZAÇÃO E PATRIMONIALIZAÇÃO NA FORMAÇÃO E DINÂMICA DO ESPAÇO TURÍSTICO

região Norte com a porção conhecida como Paraná Tradicional, para finalidade de escoamento do café (VARGAS, 2005).

De acordo com o IPARDES (1979), em 1975, dentre os principais produtos agrícolas exportados, 21 adotavam o modal ferroviário para envio de produção ao Porto de Paranaguá. O que representava cerca de $30 \%$ da carga exportada. Relatórios e informações da Rede Ferroviária Federal Sociedade Anônima (RFFSA1985) acrescentam que no período entre 1945 e 1985 o Paraná seguiu com a estruturação da malha ferroviária, cujo primeiro eixo havia sido definido pela interligação entre Paranaguá e Curitiba.

O encurtamento entre a zona da produção do Norte do Paraná, de cerca de 300 quilômetros em direção ao porto de exportação, veio baratear os fretes, a ponto de afetar, sensivelmente, o transporte rodoviário na questão das tarifas. Até então, a ferrovia não tinha condições de competir com os caminhões. A igualdade foi estabelecida com um certo equilíbrio de vantagens, surgindo um regime leal de concorrência, muito salutar ao progresso dos transportes no país e à população produtora (RFFSA, 1985, p.235).

Os modais aquaviário e aéreo, por sua vez, seguiram a tradição de baixa exploração e reduzido estímulo ao desenvolvimento. No caso do primeiro, a navegação comercial interna enfrentava dificuldades naturais, no quesito navegabilidade. Nesse sentido, Vargas (2005) lembra que o rio Iguaçu contribuiu para o processo de integração territorial do estado até o momento em que a navegação comercial foi substituída pelo transporte rodoviário, em meados dos anos 1950. Já o modal aéreo estancou frente à ausência de infraestrutura aeroportuária.

$\mathrm{Na}$ década de 1960, o investimento em infraestrutura de transportes no Paraná assumiu uma nova tônica, com ações de maior peso econômico no orçamento e no plano estratégico. Este movimento acompanhou o ritmo nacional de investimento em infraestrutura de transportes, com concentração no modal rodoviário. Segundo o IPARDES (1979), tal representou, entre 1960 e 1975, 25\% do total investido pelo governo estadual, sendo $78 \%$ da monta destinada às rodovias. No mesmo período os investimentos no modal ferroviário praticamente ficaram estagnados.

Com efeito, as décadas de 1960 e 1970 representaram momentos de intensificação na rodoviarização dos transportes. A aplicação de recursos neste 
INTEGRAÇÃO TERRITORIAL DO LITORAL DO ESTADO DO PARANÁ (BRASIL): TRANSPORTES, BALNEARIZAÇÃO E PATRIMONIALIZAÇÃO NA FORMAÇÃO E DINÂMICA DO ESPAÇO TURÍSTICO

modal chegou a $81,8 \%$ da despesa total realizada em 1977 no Paraná. Lima e Dias (2008) contabilizam que ao longo dos anos 1970 quase metade da receita estadual havia sido investida em infraestrutura, incluindo os projetos de ampliação, melhorias de pavimentação, duplicação e ampliação das rodovias mais estratégicas (BR-277 e BR-376).

Relata-se a seguinte pretensão:

[...] solidificar a economia estadual através do desenvolvimento de um programa rodoviário dinâmico, prevendo uma integração mais definitiva das áreas de produção, pela implantação de ligações asfálticas entre as zonas de influência, os centros de transformação de matérias-primas e os "corredores de exportação", que demandam ao terminal marítimo em Paranaguá (IPARDES, 1979, p. 32).

A construção da BR277 na década de 1960 tornou-se ícone do fortalecimento do modal rodoviário e da estruturação da malha paranaense, bem como de integração territorial com o Oeste do Paraná. Por meio dela foi constituído o corredor transversal de integração paranaense e também da América Latina, Rodovia Transversal Panamericana, com ligação de Paranaguá a Foz do Iguaçu, atravessando Bolívia e Paraguai, para alcançar Lima/Peru (MONTILHA e DARONCHO, 2009). O investimento na BR277 e nas demais rodovias que ligam os principais polos produtivos do estado representou o passo mais significativo em termos da organização da malha rodoviária do estado. Como corredor, a BR277 mantém articulação com a BR369, por onde escoam fluxos do Norte, e a BR373, ligada ao Sudoeste paranaense.

Como visto em Vargas (2005), a perspectiva estatal de investimento em infraestrutura de transportes começou a apresentar sinais de mudança na década de 1960. Entre 1966 e 1988, e após a extinção do Fundo Rodoviário Nacional (FRN), a prioridade que antes se concentrava na interligação viária estadual, foi substituída pela prioridade de integração regional, o que acarretou na construção de rodovias cuja finalidade era a ligação entre as cidades de cada região do estado, a exemplo da PR 408, que liga Morretes a Antonina.

Os anos 1980 constituíram um marco da mudança no rumo das ações do setor público estadual, no que se refere tanto ao sistema de integração, como aos objetivos de desenvolvimento econômico. Foram realizadas adequações e 
INTEGRAÇÃO TERRITORIAL DO LITORAL DO ESTADO DO PARANÁ (BRASIL): TRANSPORTES, BALNEARIZAÇÃO E PATRIMONIALIZAÇÃO NA FORMAÇÃO E DINÂMICA DO ESPAÇO TURÍSTICO

ampliações dos aeroportos mais importantes do estado, na Região Metropolitana de Curitiba (Aeroporto Afonso Pena) e de Foz do Iguaçu. Pode-se vislumbrar esse momento como uma etapa de crise que culminaria com a mudança de perspectiva nos anos 1990, quando as privatizações assumiram a tônica central da nova política pública de transportes, centrada na gestão privada (SILVA NETO, 2005).

$\mathrm{Na}$ Secretaria Estadual de Transportes do estado, concessão de rodovias, ferrovias e privatização dos terminais de cargas do Porto de Paranaguá se tornaram diretrizes predominantes das ações do governo estadual durante a década de 1990. Em termos de prioridade de ação, identificou-se a consolidação do Anel de Integração (SILVA NETO, 2005). A sua implementação gerou o desfecho do processo de integração, com a predominância do modal rodoviário, reforçando e reequipando a estrutura viária responsável por direcionar o fluxo de pessoas e mercadorias do estado para o eixo Curitiba-Paranaguá, sob a liderança da primeira.

\section{ESPAÇOS TURÍSTICOS NO LITORAL DO PARANÁ: O PAPEL DAS VIAS, MEIOS DE TRANSPORTE E DOS PROCESSOS DE BALNEARIZAÇÃO E PATRIMONIALIZAÇÃO}

Assim como em outros trechos de costa do Brasil e de países com hábitos e cultura turística, a formação territorial do litoral paranaense contemplou a instauração gradativa de um conjunto de espaços turísticos. Uma interpretação deste processo de configuração de tais espaços da região é possível mediante abordagem de três temáticas: (i) a constituição histórica das vias e dos meios de transporte, que integraram territórios e viabilizaram condições de acesso e mobilidade, e os processos de (ii) balnearização e (iii) patrimonialização, base da materialização de espaços turísticos regionais.

A figura 3 representa um esquema-síntese desta interpretação. Retrata um conjunto de dados secundários obtidos e sistematizados cronologicamente a partir de referências documentais (planos diretores, mapas, sítios eletrônicos do IPHAN; SECRETARIA DE ESTADO DA CULTURA; IAP-SEMA; IBGE; DNIT; IPARDES) e bibliográficos (ALVES, 2008; WACHOWICZ, 2001; BIGARELLA, 2009; LYRA, PARCHEN, LA PASTINA FILHO, 2006; NETTO, 1974; TRAMUJAS, 1996; 
INTEGRAÇÃO TERRITORIAL DO LITORAL DO ESTADO DO PARANÁ (BRASIL): TRANSPORTES, BALNEARIZAÇÃO E PATRIMONIALIZAÇÃO NA FORMAÇÃO E DINÂMICA DO ESPAÇO TURÍSTICO

ESTEVES, 2005; ROCANGLIO, 1996; SAMPAIO, 2006; PIERRE et al., 2006; FOGASSA, 2007). Sua análise segue integrada ao texto, nos capítulos seguintes.

\section{CONSTITUIÇÃO HISTÓRICA DAS VIAS E DE MEIOS DE TRANSPORTE}

O papel desempenhado pelas vias de deslocamento na configuração dos espaços turísticos requer uma análise bidimensional, inicialmente a respeito das condições de acesso territorial e da mobilidade regional, e na sequência sobre a ressignificação de alguns componentes dos sistemas de transportes e dos ambientes em que estão inseridos.

\section{ACESSO TERRITORIAL E A MOBILIDADE REGIONAL}

A instalação e aperfeiçoamento gradativo dos transportes no litoral paranaense, especialmente naquilo que se refere às condições de acesso e da mobilidade, foram motivados desde o início por seu natural posicionamento estratégico junto ao mar e pelos movimentos de integração do estado por meio dos fluxos estabelecidos entre Paranaguá e Curitiba, tendo em vista a adequação da baía de Paranaguá à função portuária.

A evolução tecnológica mundial dos transportes (equipamentos, veículos, recursos de segurança e conforto), conforme relatos de Palhares (2002) e Netto (1974), também se fez presente nesta região e deixou testemunhos materiais desse processo, sobretudo após meados do século XIX. O conjunto de aperfeiçoamentos neste setor oportunizou o deslocamento de massa, velocidades crescentes e maior capacidade de distribuição territorial.

A Estrada da Graciosa e a Estrada de Ferro Paranaguá-Curitiba representaram a modernização das condições de acesso para o litoral até que a BR 277 se consolidou, após a década de 1960, como a alternativa de conexão dominante e espinha dorsal das vias regionais. O rodoviarismo cresceu e expandiu sua influência, sobretudo após o desmantelamento do modal ferroviário no Brasil na segunda metade do século XX (VARGAS, 2005). 
CHEMIN, M.; ABRAHÃO, C.M.S.

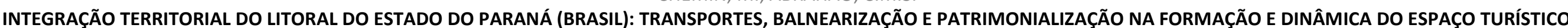

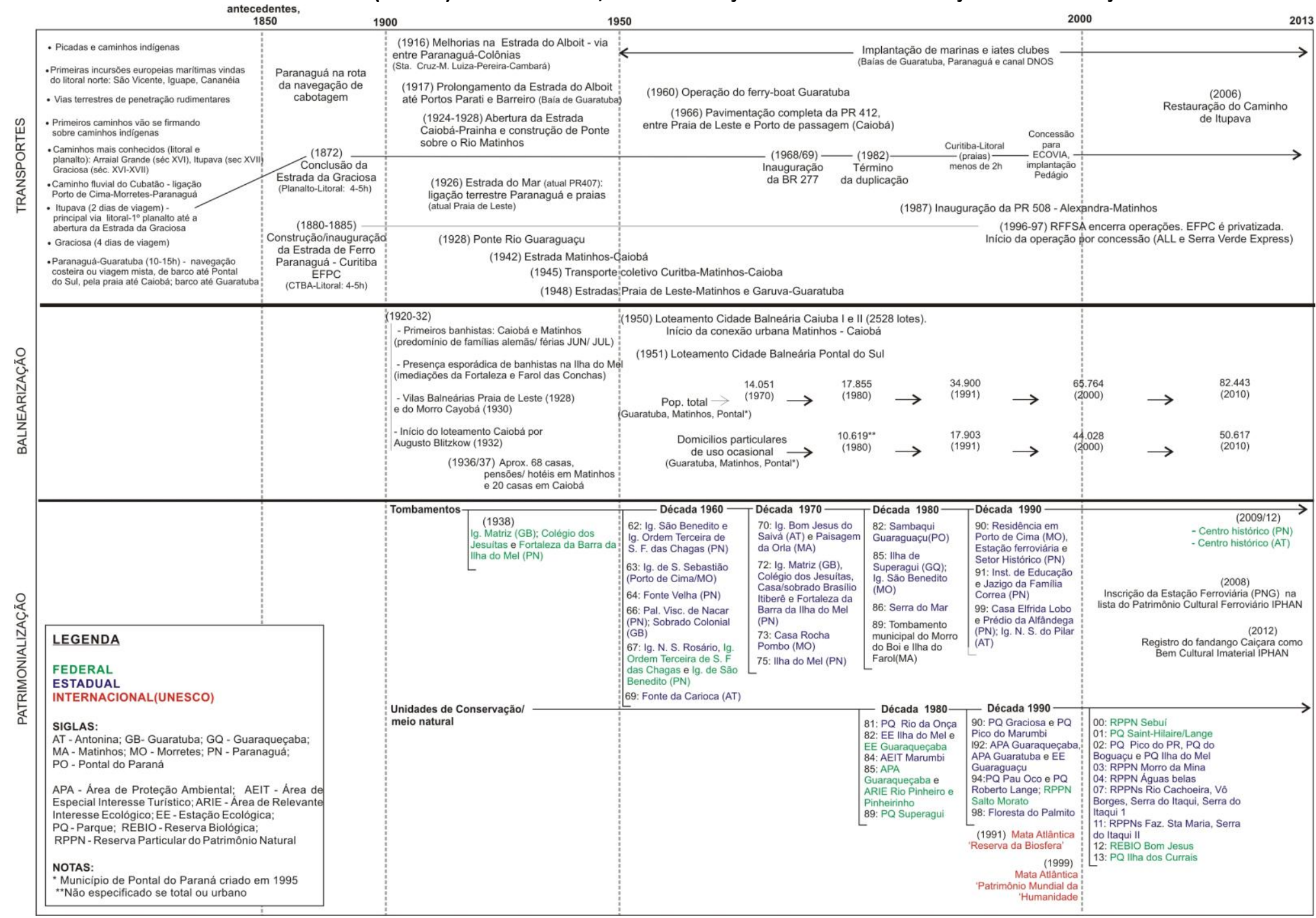

Figura 3: Desenvolvimento dos transportes, da balnearização e da patrimonialização no litoral do Paraná.

Organização: Marcelo Chemin (2013). 
INTEGRAÇÃO TERRITORIAL DO LITORAL DO ESTADO DO PARANÁ (BRASIL): TRANSPORTES, BALNEARIZAÇÃO E PATRIMONIALIZAÇÃO NA FORMAÇÃO E DINÂMICA DO ESPAÇO TURÍSTICO

Como já demonstrado, o conjunto das vias existentes na região revela sua origem atrelada à necessidade de escoamento de produção. Ligações intrarregionais, entre cidades e demais núcleos povoadores, também impulsionaram a instalação dos sistemas de transportes, todavia em menor dimensão. Os fluxos turísticos apenas se beneficiaram dos sistemas e das suas estruturas, inicialmente a partir da década de 1920, mais intensamente após a década de 1980 (BIGARELLA, 2009; SAMPAIO, 2006).

A operação do Ferry-Boat de Guaratuba em 1960 e a construção de três estradas estaduais evidenciam o interesse de melhor acesso e distribuição de fluxos junto às praias, quais sejam: Estrada do Mar (década de 1920), atual PR407; PR 412 (final da década de 1940) e PR 508 (final da década de 1980), conhecida como Alexandra - Matinhos (BIGARELLA, 2009; PDDI Matinhos ${ }^{10}$, 2006; PDDI Guaratuba $^{11}$, 2002). Estes quatro integrantes do sistema de transporte regional alteraram as condições de acesso e de mobilidade territorial próximo às praias e interferiram significativamente na configuração de espaços turísticos, especialmente daqueles situados no âmbito dos três municípios balneários: Guaratuba, Matinhos e Pontal do Paraná.

Como visto, a rodovia federal BR 277 é o eixo dominante de integração, com sentido Leste - Oeste e posicionamento central na região, além de conexão direta entre Curitiba e Paranaguá. Em maior escala, levando-se em conta a lógica das redes de transportes, Curitiba figura como o polo urbano mais próximo do litoral (65Km de Morretes) e também o mais populoso (1.751 milhão). Considerando-se a Região Metropolitana de Curitiba, 9ª mais populosa do Brasil, são 3.174 milhões de habitantes (IBGE, 2013) residentes a uma distância inferior a $110 \mathrm{~km}$ do Litoral, ou seja, acesso ao destino após deslocamento de aproximadamente $1 \mathrm{~h} 45 \mathrm{~min}$.

As demais estradas do litoral são secundárias na função de ligação interestadual e configuram, segundo conceito de Palhares (2002), uma rede do tipo linear, condicionada no desenho pelo perfil geográfico regional, com imperativos geológicos, como a Serra do Mar e as Baías de Paranaguá e Guaratuba. As

\footnotetext{
${ }_{11}^{10}$ Plano Diretor Participativo e de Desenvolvimento Integrado de Matinhos (2006).

${ }^{11}$ Plano Diretor de Desenvolvimento Integrado de Guaratuba, 2002.
} 

INTEGRAÇÃO TERRITORIAL DO LITORAL DO ESTADO DO PARANÁ (BRASIL): TRANSPORTES, BALNEARIZAÇÃO
E PATRIMONIALIZAÇÃO NA FORMAÇÃO E DINÂMICA DO ESPAÇO TURÍSTICO

estradas estaduais viabilizam as conexões intra-regionais ${ }^{12}$, tendo a BR 277 como espinha dorsal.

Além do rodoviário, outro modal ${ }^{13}$ de transporte que dinamiza este litoral e contribui para a definição dos espaços turísticos é o aquaviário. Embora a perspectiva deste modal esteja bastante vinculada à questão portuária e ao transporte de cargas, em razão do Porto de Paranaguá e Antonina, inúmeras comunidades e espaços alternativos de lazer e turismo estão estabelecidos ao longo do Complexo Estuarino de Paranaguá e na Baía de Guaratuba (CHEMIN e ABRAHÃO, 2013).

Com efeito, a integração de tais espaços implica em demanda permanente de serviços de navegação, embarcações entre outros elementos que tipificam este modal. Somente o Complexo Estuarino de Paranaguá (CEP) comporta baías (p. ex. Laranjeiras, Pinheiros), enseadas (ex. Benito, Itaqui e Medeiros), além de um complexo insular (p. ex., Ilhas do Mel e das Cobras) cuja integração se efetiva pela via marítima.

À exceção de Morretes, as outras seis sedes urbanas dos municípios litorâneos mantêm relação de contiguidade territorial com o mar ou as baías. Píeres, cais e atracadouros são equipamentos comuns na paisagem destas cidades, do mesmo modo que 'estacionamentos' de barcos e assemelhados em trechos de praia. Importantes polos do turismo regional como a llha do Mel, Guaraqueçaba e Superagui mantêm permanentes fluxos de transporte deste gênero, que se desenvolve primordialmente em rotas sobre as águas protegidas da baía de Paranaguá (CHEMIN, 2011; NARDI, 2011; CHEMIN e ABRAHÃO, 2013).

\footnotetext{
${ }^{12}$ A porção Norte do litoral é articulada pelas PR 804, 405, 408, 410, 411 e 340, vias de conexão entre Morretes, Antonina, Guaraqueçaba e também com o primeiro planalto, por meio da Graciosa (PR 410). Na porção Sul, a PR 407 e PR 508 efetivam a conexão entre a BR 277 e a PR 412, rodovia estadual longitudinal que margeia a costa praiana e estrutura a integração entre Pontal do Sul, Matinhos e Guaratuba, até Santa Catarina, onde está ligada a SC 412.

${ }_{13}$ Para visualização da rede de transportes na região litorânea, no Estado do Paraná ou da integração nacional, sugere-se consulta ao Mapa Multimodal do DNIT, disponível em: http://www.dnit.gov.br/mapas-multimodais/mapas-multimodais.
} 
INTEGRAÇÃO TERRITORIAL DO LITORAL DO ESTADO DO PARANÁ (BRASIL): TRANSPORTES, BALNEARIZAÇÃO E PATRIMONIALIZAÇÃO NA FORMAÇÃO E DINÂMICA DO ESPAÇO TURÍSTICO

\section{RESSIGNIFICAÇÃO DE COMPONENTES DOS SISTEMAS DE TRANSPORTES E DE AMBIENTES}

Outro ponto determinante, tanto para a configuração dos espaços turísticos, como para a própria sustentação das atividades produtivas do turismo, diz respeito à alteração semântica de componentes que estruturam ou dão suporte para os sistemas de transportes e os ambientes em que estão inseridos (URRY, 2001; COELHO NETO, 2007). As próprias estruturas de transporte e os ambientes de entorno receberam acréscimos semânticos ${ }^{14}$ a ponto de se tornarem em si atrações à parte.

Além do papel de origem do sistema de transporte, ou seja, mobilidade territorial entre polos de origem e destino, o desenvolvimento do turismo na região demandou a instauração de funções específicas, que, paralelo ao avanço do paradigma ambiental e da atmosfera patrimonial presente na região, modificaram a carga semântica de determinados elementos de infraestrutura (vias, equipamentos, outros). Gradativamente, estes elementos passaram a se constituir eles próprios em objetos de fruição das práticas e discursos do turismo - especialmente da publicidade especializada.

Isto promoveu, como primeiro exemplo, o caminho colonial do Itupava como uma das principais atrações turísticas da região. A perda de sua função original, deslocamento entre planície e primeiro planalto, não acarretou seu completo desuso, mas ao contrário, a rota mantém-se ativa em determinados nichos por meio da função turística. Tornou-se um objeto das práticas de turismo, com imagem associada à aventura e a oportunidade de vivência de um patrimônio regional inserido no exotismo da mata atlântica (CHEMIN e ABRAHÃO, 2013).

No caso do Complexo Estuarino de Paranaguá e da Baía de Guaratuba, o status contemporâneo da natureza "preservada" e "santuário" ecológico projetam um conjunto de atributos semânticos sobre estes ambientes. Após a década de 1950, marinas e iates clubes foram instaladas no domínio destes ambientes e de seus arredores (CHEMIN e ABRAHÃO, 2013; PIERRE et al., 2006). Nada mais são do

\footnotetext{
${ }^{14}$ Análise pautada teoricamente em Urry (2001) e Coelho Neto (2007). Urry (2001) indica que tanto significados sociais, como os imaginários, implicam em efeitos sobre a organização espacial e na redefinição de expectativas e imagens turísticas. Coelho Neto (2007) explica como os processos de semantização espacial ocorrem em razão de práticas e 'discursos' sobre o espaço.
} 
INTEGRAÇÃO TERRITORIAL DO LITORAL DO ESTADO DO PARANÁ (BRASIL): TRANSPORTES, BALNEARIZAÇÃO E PATRIMONIALIZAÇÃO NA FORMAÇÃO E DINÂMICA DO ESPAÇO TURÍSTICO

que a resultante de um processo que constituiu o mar em ambiente de relaxamento social e da navegação, pescaria, passeios de barco, entre outras atividades náuticas, o recurso necessário para efetivação destas práticas.

De modo semelhante, a Estrada da Graciosa e a Estrada de Ferro Paranaguá-Curitiba enfraqueceram-se em suas funções originais de deslocamento de passageiros e cargas entre a planície litorânea e o primeiro planalto, fato este especialmente derivado da prevalência do rodoviarismo na região. A consolidação da BR 277 possibilitou, no entanto, novos delineamentos das funções e dos significados destas duas estradas (CHEMIN e ABRAHÃO, 2013).

Ambas, inseridas no "santuário" ecológico da mata atlântica, tornaram-se equipamentos fundamentais do turismo regional. Simultaneamente, desempenham função, tanto como meios de acesso como atrações locais. Do mesmo modo que usos turísticos são estabelecidos ao longo da Estrada da Graciosa, por meio de um conjunto de recantos instalados, a Estrada de Ferro (trilhos, pontes, estações, viadutos, túneis), e até mesmo o patrimônio da Rede Viação Paraná Santa Catarina, em estado de arruinamento em diversos pontos, se convertem em objetos do interesse turístico (CHEMIN e ABRAHÃO, 2013).

\section{BALNEARIZAÇÃO E O NASCIMENTO DE 'CIDADES-PRAIA'}

Interpreta-se balnearização como o processo que sintetiza a interação entre o desenvolvimento do uso balneário (URRY, 2001; PEARCE, 2003; O'DONNELL, 2013; FERREIRA E SILVA, 2001), a apropriação turística da costa continental paranaense e sua urbanização (BIGARELLA, 2009; SAMPAIO, 2006). Decorre de uma dialética entre a projeção simbólica da praia como ambiente de lazer e fruição e a instauração de um conjunto de práticas, rituais e relações socioeconômicas, cuja implicação é a produção de dinâmicas e espaços destinados prioritariamente a usuários provisórios.

De modo semelhante a outros territórios litorâneos mundo afora, no litoral do Paraná áreas urbanas e espaços turísticos eclodiram como efeito da difusão dos hábitos de veraneio e da efervescência cultural do prazer praiano. Matinhos ${ }^{15} \mathrm{e}$

\footnotetext{
${ }^{15} \mathrm{Em} 1951$ Matinhos era Distrito subordinado à Paranaguá (Lei estadual 613). Criado como município em 1968 (IBGE, 2013).
} 
INTEGRAÇÃO TERRITORIAL DO LITORAL DO ESTADO DO PARANÁ (BRASIL): TRANSPORTES, BALNEARIZAÇÃO E PATRIMONIALIZAÇÃO NA FORMAÇÃO E DINÂMICA DO ESPAÇO TURÍSTICO

Pontal do Paraná $^{16}$, conformadas por sucessivos balneários que seguem a linearidade da costa e da PR 412, representam os exemplos mais puros da concretização espacial do processo de balnearização. Guaratuba, cuja fundação remonta ao século XVIII, difere no aspecto "origem" destes dois municípios. Apesar disso, do mesmo modo que Matinhos e Pontal do Paraná a expansão ${ }^{17}$ do quadro urbano acelerou na segunda metade do século XX como implicação da balnearização (CHEMIN e ABRAHÃO, 2013).

De acordo com registros de Bigarella (2009), Sampaio (2006), Athayde e Britez (2005), o início do uso balneário no Paraná se deu na década de 1920, com presença de banhistas nas imediações do Pico de Matinhos, do Morro de Caiobá e na llha do Mel (próximo ao farol e fortaleza). Esta década marcou então o "nascimento" da praia como um "novo" território deste litoral e a sua incorporação na vida social dos paranaenses. Demarcou também o início da urbanização tipicamente balneária e da integração da economia (ainda que em níveis modestos) do turismo na região, antes concentrada nas cidades de Paranaguá, Morretes, Antonina, em função da atividade portuária e da ferrovia.

A abertura de estradas intra-regionais, iniciada também na década de 1920, e o gradativo aperfeiçoamento das vias de acesso e meios de transporte, tanto ao litoral, como à orla continental, a partir de Paranaguá, constituiu o fator decisivo à aceleração da urbanização de balneários em Matinhos, Pontal do Sul e Guaratuba (BIGARELLA, 2009; SAMPAIO, 2006; PDDI Matinhos, 2006; PDDI Guaratuba, 2002). No âmbito regional, maior contribuição é vista, pelo Norte, na Estrada do Mar (atual PR 407), que ligou Paranaguá à costa oceânica em 1926 e, pelo Sul, a abertura da estrada Garuva-Guaratuba em 1948.

Acompanhando o ritmo de crescimento das práticas sociais de uso da praia, os assentamentos foram se transformando em pequenas vilas, onde eram encontrados os serviços básicos necessários à estadia das famílias e grupos pioneiros. Nos anos de 1936 e 1937 não passavam de 100 as edificações em Matinhos e Caiobá (BIGARELLA, 2009). Na década de 1950 o lançamento dos

\footnotetext{
${ }^{16}$ Criado como município em 1995, antes era Distrito subordinado à Paranaguá (Lei estadual 8915) (IBGE, 2013).

17 Informações sobre implantação de loteamentos e expansão do quadro urbano no Plano Diretor Participativo e de Desenvolvimento Integrado de Matinhos (PDPDI, 2006).
} 
INTEGRAÇÃO TERRITORIAL DO LITORAL DO ESTADO DO PARANÁ (BRASIL): TRANSPORTES, BALNEARIZAÇÃO E PATRIMONIALIZAÇÃO NA FORMAÇÃO E DINÂMICA DO ESPAÇO TURÍSTICO

loteamentos Cidades Balneárias Caiuba I, II e Pontal do Sul (BIGARELLA, 2009; SAMPAIO, 2006; PDPDI Matinhos, 2006) significou a mudança definitiva de uma orla continental ocupada por poucos vilarejos, de ruas de traçado irregular, sem calçamento e edificações na sua maioria de madeira, para uma orla intensamente balnearizada.

O processo de balnearização, intensificado a partir da década de 1960 configurou na orla continental ao Sul da Baía de Paranaguá uma faixa urbana longitudinal, praticamente sem interrupções entre Pontal do Sul e Guaratuba (MOURA e WERNECK, 2000; DESCHAMPS e KLEINKE, 2000; SAMPAIO, 2006; PDPDI Matinhos, 2006). Dentre as principais características deste tipo de urbanização, destacam-se:

a) predomínio de áreas residenciais, com baixa densidade populacional, uma vez que os imóveis correspondem a $2^{\text {a }}$ residência. Em Guaratuba, Matinhos e Pontal, no ano de 2010, a relação de imóveis particulares de uso ocasional por habitante era de 1,63;

b) traçado urbano ortogonal, com presença de inúmeros condomínios verticais (nas primeiras quadras) e horizontais, complexos de hospedagem e lazer de associações e entidades de classe, empresas de hospedagem e comércio de serviços de pequeno porte;

c) alta subordinação a processos de especulação imobiliária;

d) verticalização nas áreas mais próximas ao mar, estas em geral, mais valorizadas, devido à paisagem e a proximidade da praia;

e) acentuada precarização das condições de infraestrutura nas porções urbanas mais distantes da praia;

f) carência de equipamentos culturais e de lazer;

g) cidades lineares "sem centro", com comércio e serviços altamente concentrado nas vias principais, que são também as vias de acesso e articulação regional (p. ex. PR 412).

Neste contexto, o processo de balnearização produziu como seus principais espaços turísticos no litoral do Paraná as orlas de Guaratuba, Caiobá (Matinhos) e de Praia de Leste (Pontal do Sul). Embora haja outras orlas nestes municípios, são 
INTEGRAÇÃO TERRITORIAL DO LITORAL DO ESTADO DO PARANÁ (BRASIL): TRANSPORTES, BALNEARIZAÇÃO E PATRIMONIALIZAÇÃO NA FORMAÇÃO E DINÂMICA DO ESPAÇO TURÍSTICO

estes três recortes espaciais que concentram maior volume de frequentação turística, serviços, práticas e rituais próprios do turismo.

\section{PATRIMONIALIZAÇÃO DA HISTÓRIA E DA NATUREZA}

Patrimonialização é outro processo que definiu espaços turísticos no litoral do Paraná. De início faz referência a um conjunto de medidas de natureza política e administrativa cuja finalidade é o registro pela via oficial do valor histórico e ecológico presente neste território (LYRA, PARCHEN, LA PASTINA FILHO, 2006; FOGASSA, 2007). Em segundo momento, compreende-se que a instauração de patrimônios, entre outras finalidades, reforça a imagem turística da região, acompanhando a forte associação simbólica entre patrimônio e as práticas do turismo.

De um lado este processo mantém filiação com o reconhecimento político e a difusão da noção de patrimônio, operada mais fortemente no debate cultural do século $\mathrm{XX}$, com participação de governos, instituições de educação e cultura e organismos nacionais e internacionais de defesa e promoção. Em outra frente, a patrimonialização encontrou sustentação no paradigma ecológico, pauta de âmbito internacional que ganhou fôlego após a década de 1970 (FRANCO, 2000; CHOAY, 2001; MENESES, 2002; SEIFFERT, 2007; YAZIGI, 2001 e 2009).

Desde a década de 1930 sucessivas medidas de inventários, tombamentos, implantação de unidades de conservação e declarações internacionais instituíram na região um mosaico diversificado de bens culturais e naturais. São medidas oficiais, que visam proteção e que definem restrições, direitos e obrigações (LYRA, PARCHEN, LA PASTINA FILHO, 2006; FOGASSA, 2007), com implicações variadas sobre as formas de uso do território e no cotidiano social.

As primeiras ações de patrimonialização remontam ao ano de 1938, com o tombamento federal da Igreja Matriz de Guaratuba, do Colégio dos Jesuítas em Paranaguá e da Fortaleza da Barra na llha do Mel (LYRA, PARCHEN, LA PASTINA FILHO, 2006; FOGASSA, 2007). As próximas ações foram efetivadas nas décadas de 1960 e 1970, por intermédio da união e do estado, mantendo-se atenção ao patrimônio cultural edificado, sobretudo, bens da arquitetura religiosa. 
INTEGRAÇÃO TERRITORIAL DO LITORAL DO ESTADO DO PARANÁ (BRASIL): TRANSPORTES, BALNEARIZAÇÃO E PATRIMONIALIZAÇÃO NA FORMAÇÃO E DINÂMICA DO ESPAÇO TURÍSTICO

Nas duas décadas seguintes o processo da patrimonialização se dividiu em duas frentes. A primeira manteve ações de proteção do patrimônio cultural e maior atenção a sítios e contextos geográficos mais amplos. Nesse sentido, destacam-se os tombamentos estaduais do sambaqui do Guaraguaçu, da llha de Superagui, da Serra do Mar e do Setor Histórico de Paranaguá (LYRA, PARCHEN, LA PASTINA FILHO, 2006; FOGASSA, 2007). A segunda frente diz respeito ao início de criação de unidades de proteção ambiental sob a figura de parques, estações ecológicas, áreas de especial interesse turístico, outras.

Para Carneiro (2007) a questão da proteção ambiental no Paraná está associada, em sua origem, a aspectos que constituem elementos patrimoniais da cultura regional. Representou, no início do século XX, uma reivindicação importante do movimento paranista em busca de paisagens típicas do Paraná. Esteve também associada à proteção do sistema natural de abastecimento hídrico da capital. No geral, isto se traduziu, conforme Carneiro (2007), na "Bandeira Paranaense de Turismo", que atuou no sentido de despertar interesse nos habitantes de Curitiba pelas paisagens paranaenses, em especial, na Serra do Mar.

$\mathrm{Na}$ década de 1990 duas medidas fortaleceram a atmosfera patrimonial da região, a saber: o reconhecimento internacional da mata atlântica como Reserva da Biosfera e sua integração na seleta lista de Patrimônios Mundiais da Humanidade da UNESCO. As ações seguintes, no início do novo século, mantiveram as duas frentes. Foram demarcados novos parques estaduais e nacionais, reserva biológica e reservas particulares do patrimônio natural. De outro modo, o tombamento federal dos centros históricos de Paranaguá e Antonina (IPHAN, 2013) firmou a tendência contemporânea de prevalência de proteção de conjuntos ao invés de bens isolados.

A patrimonialização não responde pela produção direta de estruturas espaciais como se viu na análise sobre a balnearização, todavia a conversão simbólica de componentes e porções do território em bens e sítios patrimoniais exerce influência na dinâmica espacial, mediante novas funções, instalações e atividades específicas, bastante ligadas ao turismo. Assim, no litoral paranaense, os principais locais patrimonializados projetados como espaços turísticos são: centros históricos de Paranaguá e Antonina; o complexo da Serra do Mar; Ilha do Mel; Parque de Superagui, Estradas da Graciosa e de Ferro Paranaguá-Curitiba, 
INTEGRAÇÃO TERRITORIAL DO LITORAL DO ESTADO DO PARANÁ (BRASIL): TRANSPORTES, BALNEARIZAÇÃO E PATRIMONIALIZAÇÃO NA FORMAÇÃO E DINÂMICA DO ESPAÇO TURÍSTICO

Conjunto Marumbi (CHEMIN e ABRAHÃO, 2013; CARNEIRO, 2007; FOGASSA, 2007).

Por fim, o patrimônio imaterial também exerce influência na dinâmica dos espaços turísticos da região, conforme demonstrou Gimenes (2009) ao estudar o barreado, prato que vincula gastronomia e turismo no litoral do Paraná e é degustado há anos, associado historicamente às manifestações populares do fandango e do carnaval. Antonina e Morretes são os municípios em que este processo de associação entre a oferta de pratos expressivos do patrimônio cultural e a atividade turística mais se evidenciam.

\section{CONSIDERAÇÕES FINAIS}

A análise presente neste artigo, que resulta do desenvolvimento de uma pesquisa regional, evidenciou um recorte das dinâmicas e das configurações do turismo no litoral paranaense. A contextualização histórica demonstrou características multifacetadas da formação desse território e da sua integração a contextos mais amplos, situando o início da produção de espaços turísticos como efeito do uso social da praia como espaço de lazer.

A articulação entre pesquisa bibliográfica, documental e a disposição cronológica de dados e informações, permitiu conhecer parte do processo de desenvolvimento do turismo e de suas formas espaciais neste litoral, no contexto da integração territorial, dos meios de acesso e transportes. Os processos de balnearização e patrimonialização, ainda que em estágio preliminar de interpretação, se firmaram ao longo dos estudos e reflexões como duas expressões fundamentais do turismo e da configuração de espaços turísticos nesta região.

Entende-se ser necessário o avanço de outras frentes de pesquisa, sobretudo maior atenção à pesquisa documental, a respeito da formação territorial da região $\mathrm{e}$ da dimensão espacial do turismo. A bibliografia escassa é um grande obstáculo ao aperfeiçoamento da investigação desses temas. Além disso, embora as estatísticas de fluxos turísticos sejam quantitativamente positivas, em virtude dos balneários e do acervo patrimonial, compreende-se que a qualificação do turismo regional requer uma postura estratégica de governos e atores envolvidos. Para tanto, o panorama das relações territoriais do turismo precisa ser constantemente desvelada. 
INTEGRAÇÃO TERRITORIAL DO LITORAL DO ESTADO DO PARANÁ (BRASIL): TRANSPORTES, BALNEARIZAÇÃO E PATRIMONIALIZAÇÃO NA FORMAÇÃO E DINÂMICA DO ESPAÇO TURÍSTICO

\section{REFERÊNCIAS}

CHEMIN, M.; ABRAHÃO, C.M.S. Dinâmicas e configurações da atividade turística no litoral do Paraná. Matinhos: UFPR (Setor Litoral), Pesquisa/Relatório (n.1). 2013.

ALVES, N.L.P. As montanhas do Marumbi. Curitiba: edição do autor, 2008.

ATHAYDE, S.F.; BRITEZ, R.M. As unidades de conservação. In: MARQUES, M.C.M.; BRITEZ, R.M. (orgs.). História natural e conservação da llha do Mel. Curitiba: editora da UFPR, 2005.

BIGARELLA, J.J. Matinho: homem e terra, reminiscências [...]. Curitiba: Fundação Cultural de Curitiba, 2009.

CARNEIRO, C.F.A.G. A constituição de patrimônios naturais e o tombamento da serra do mar no Paraná. Tese (doutorado) - Universidade Federal do Paraná, Programa de Pós-Graduação em Meio Ambiente e Desenvolvimento. Curitiba, 2007.

CHEMIN, M. Constituição fisionômica e identidade visual em espaços de paisagens: um estudo de caso múltiplo em cidades turísticas do litoral do Paraná. Tese (Doutorado em Geografia). UFPR, Curitiba, 2011.

CHOAY, F. A alegoria do patrimônio. São Paulo: Editora UNESP, 2001.

CLAVÉ, S.A. Paisajes temáticos. In: BUSQUETS, J.; CORTINA, A. Gestión del paisaje: manual de protección, gestión y ordenación del paisaje. Barcelona: Ariel, 2009.

La urbanización turística. De la conquista del viaje a la reestructuración de la ciudad turística. Doc. Anàl. Geogr., v. 32, n. 12, 1998.

COELHO NETTO, J.T. A construção do sentido na arquitetura. São Paulo: Perspectiva, 2007.

COLAVITE, A.P. Contribuição do geoprocessamento para criação de roteiros turísticos nos caminhos de Peabiru - PR. Dissertação (Mestrado). Programa de Mestrado em Geografia, Meio Ambiente e Desenvolvimento, Universidade Estadual de Londrina, Londrina, 2006.

CORNELSEN, C.A. Turismo em áreas naturais do Paraná. Curitiba: PUCPR, Material didático. 2000. 
INTEGRAÇÃO TERRITORIAL DO LITORAL DO ESTADO DO PARANÁ (BRASIL): TRANSPORTES, BALNEARIZAÇÃO E PATRIMONIALIZAÇÃO NA FORMAÇÃO E DINÂMICA DO ESPAÇO TURÍSTICO

ESTEVES, C.J.O. Ocupação do litoral paranaense. In: SCORTEGAGNA, A.; REZENDE, C.J.; TRICHES, R.I. Paraná espaço e memória: diversos olhares histórico-geográficos. Curitiba: Editora Bagozzi, 2005.

FERREIRA E SILVA, M.G. A praia e o imaginário social: discurso médico e mudança de significados na cidade do Rio de Janeiro. In: CORRÊA, R.L.; ROSENDAHL, Z. (Orgs.). Paisagem, imaginário e espaço. Rio de Janeiro: EdUERJ, p. 9-28. 2001.

FOGASSA, H. (Coord.). Instrução do processo de tombamento do setor histórico de Paranaguá. Curitiba: IPHAN/PR, 2007.

FRANCO, M.A.R. Planejamento ambiental para a cidade sustentável. São Paulo: Annablume: FAPESP, 2000.

GIL, T.L. Coisas do caminho - Tropeiros e seus negócios do Viamão à Sorocaba (1780-1810). [Tese Doutorado] Programa de Pós-Graduação em História Social. Universidade Federal do Rio de Janeiro, Rio de Janeiro, 2009.

GIMENES, M.H.S.G. Cozinhando a tradição: festa, cultura e história no litoral paranaense. Tese de Doutorado. Tese (Doutorado em História)-Setor de Ciências Humanas, Letras e Artes, Universidade Federal do Paraná, Curitiba. 2008.

GODOY, A.M.G. Um Olhar sobre a cidade de Paranaguá: Os impactos sócioambientais das mudanças portuárias. [Tese de Doutorado]. Pós-graduação em Meio Ambiente e Desenvolvimento, UFPR, Curitiba, 1998.

IBGE. Instituto Brasileiro de Geografia e Estatística. IBGE Cidades@. Disponível em: <http://www.ibge.gov.br/cidadesat/index.php>. Acesso em 10/07/2013.

IPARDES. Instituto Paranaense de Desenvolvimento Econômico e Social. Subsídios ao diagnóstico socioeconômico do Paraná - inventário de infraestrutura $-2^{\underline{a}}$ fase - transporte rodoviário, Curitiba: IPARDES, 1979.

IPHAN. Instituto do Patrimônio Histórico e Artístico Nacional. Lista dos Bens Culturais Inscritos no Livro do Tombo (1938-2012). Disponível em: $<$ http://www.iphan.gov.br/baixaFcdAnexo.do?id=3263>. Acesso em 12/08/2013.

KROETZ, L.R. As estradas de ferro do Paraná - 1880-1940. (Tese) Doutorado. USP, São Paulo, 1985. 
INTEGRAÇÃO TERRITORIAL DO LITORAL DO ESTADO DO PARANÁ (BRASIL): TRANSPORTES, BALNEARIZAÇÃO E PATRIMONIALIZAÇÃO NA FORMAÇÃO E DINÂMICA DO ESPAÇO TURÍSTICO

LEANDRO, J.A. Devastação e tráfico de madeira no Litoral do Paraná Provincial. IN: Revista de História Regional. 4(2), p. 93-105. 1999.

Gentes do Grande Mar Redondo: riqueza e pobreza na comarca de Paranaguá. 1850 - 1888. (Tese) Doutorado em História. UFSC, Florianópolis, 2003.

LINHARES, T. História econômica do mate. Rio de Janeiro: José Olympio, 1969.

LOZATO-GIOTARD, J.P. Geografía del turismo: del espacio contemplado al espacio consumido. Barcelona: Masson, 1990.

LYRA, C.I.C.O.; PARCHEN, R.C.A.; LA PASTINA FILHO, J. Espirais do tempo: bens tombados do Paraná. Curitiba: Secretaria de Estado da Cultura, 2006.

MENESES, U.B. A paisagem como fato cultural. In: YÁZIGI, E. (Org.). Turismo e paisagem. São Paulo: Contexto, p. 29-64. 2002.

MONTILHA, A.C.; DARONCHO, C. Desenvolvimento de novas rotas para exportação através dos corredores bioceânicos e a integração sulamericana. Monografia pela CBTU (Companhia Brasileira de Trens Urbanos), 2009.

MOURA, R.; WERNECK, D.Z. Ocupação contínua litorânea do Paraná: uma leitura do espaço. Revista Paranaense de Desenvolvimento. Curitiba, n. 99, p. 6182, jul./dez. 2000

NETTO, F.F. 150 anos de transportes no Brasil. Rio de Janeiro, Centro de Documentação e Publicações - Ministério do Transportes, 1974.

NARDI, L. Centro histórico de Paranaguá (PR): usos e sentidos na cidade contemporânea. Dissertação (Mestrado) - Programa de Pós Graduação em Urbanismo, História e Arquitetura da Cidade, Universidade Federal de Santa Catarina, Florianópolis, 2011.

O'DONNELL, J. A invenção de Copacabana: culturas urbanas e estilos de vida no Rio de Janeiro (1890-1940). Rio de Janeiro: Zahar, 2013.

OLIVEIRA, M.C. Estudo da Erva-Mate no Paraná: 1939-1967. Dissertação (Mestrado) - Programa de Pós-Graduação em História, Universidade Federal do Paraná, Curitiba, 1974. 
INTEGRAÇÃO TERRITORIAL DO LITORAL DO ESTADO DO PARANÁ (BRASIL): TRANSPORTES, BALNEARIZAÇÃO E PATRIMONIALIZAÇÃO NA FORMAÇÃO E DINÂMICA DO ESPAÇO TURÍSTICO

PADIS, P.C. Formação de uma economia periférica: o caso Paraná. São Paulo: Hucitec, Curitiba: Secretaria da Cultura e do Esporte do Governo do Estado do Paraná, 1981.

PALHARES, G.L. Transportes turísticos. São Paulo: Aleph, 2002.

PEARCE, D. Geografia do turismo: fluxos e regiões no mercado de viagens. São Paulo: Aleph, 2003.

PIERRI, N.; ÂNGULO, R.J.; SOUZA, M.C.; KIM, M.K. A ocupação e o uso do solo no litoral paranaense: condicionantes, conflitos e tendências. Desenvolvimento e Meio Ambiente, ㄲo 13, Curitiba: UFPR, p. 137-167. 2006.

PLANO DIRETOR DE DESENVOLVIMENTO INTEGRADO. Prefeitura Municipal de Guaratuba, 2002.

PLANO DIRETOR PARTICIPATIVO E DE DESENVOLVIMENTO INTEGRADO DE MATINHOS (Cadernos 1 e 2 - Diagnóstico). Prefeitura Municipal de Matinhos, 2006.

RFFSA. Rede Ferroviária Federal S.A. Ferrovia Paranaguá-Curitiba: 1885 - 2 de Fevereiro de 1985. Curitiba, 1985.

ROCANGLIO, C. Das estradas às rodovias: meio século do rodoviarismo do Paraná. Curitiba: DER: DEAP, 1996.

SAINT-HILAIRE, A. Viagem a Curitiba e província de Santa Catarina. São Paulo: Ed. Villa Rica, 1978.

SAMPAIO, R.. Ocupação das orlas das praias paranaenses pelo uso balneário. Desenvolvimento e Meio Ambiente. Editora UFPR, N. 13. P. 169-186. Jan./jun. 2006.

SCHEIFFER, B. Paranaguá, cidade portuária: entre a cidade sonhada e a cidade real. Dissertação (Mestrado) - Programa de Pós-graduação em História, Universidade Estadual do Oeste do Paraná, Marechal Cândido Rondon, 2008.

SEIFFERT, M.E.B. Gestão ambiental: instrumentos, esferas de ação e educação ambiental. São Paulo: Atlas, 2007.

SILVA NETO, A.V. As políticas públicas de Transportes no Paraná: uma análise do governo Jaime Lerner - 1995-2002. Dissertação (Mestrado) - Programa de Pós-Graduação em Desenvolvimento Econômico, UFPR, Curitiba, 2005. 
INTEGRAÇÃO TERRITORIAL DO LITORAL DO ESTADO DO PARANÁ (BRASIL): TRANSPORTES, BALNEARIZAÇÃO E PATRIMONIALIZAÇÃO NA FORMAÇÃO E DINÂMICA DO ESPAÇO TURÍSTICO

SILVA, L.C.K. Tropeirismo. In: SCORTEGAGNA, A.; REZENDE, C.J.; TRICHES, R.I. Paraná espaço e memória: diversos olhares histórico-geográficos. Curitiba: Editora Bagozzi, 2005.

STRAFORINI, R. Tramas que brilham: sistema de circulação e a produção do território brasileiro no século XVIII. Tese (Doutorado). Programa de Pós-graduação em Geografia, Universidade Federal do Rio de Janeiro, Rio de Janeiro, 2007.

TRAMUJAS, A. Histórias de Paranaguá: dos pioneiros da Cotinga à porta do Mercosul no Brasil Meridional. Curitiba: s. ed., 1996.

VARGAS, C.R. Paraná: Desenvolvimento e Transportes. Dissertação (Mestrado) Mestrado em Desenvolvimento Econômico, Universidade Federal do Paraná, Curitiba, 2005.

VEGA, J.L.G. Ócio e turismo. Rio de Janeiro: SALVAT Brasil, 1979.

URRY, J. O olhar do turista. São Paulo: Nobel, 2001.

WACHOWICZ, R. Paraná: a comunicação histórica do mar-oceano ao rio-mar. IN: Revista Paranaense de Desenvolvimento, Curitiba, n. 83, set/dez 1994.

. História do Paraná. Curitiba: Imprensa Oficial do Paraná, 2001.

YÁZIGI, E. A alma do lugar: turismo, planejamento e cotidiano em litorais e montanhas.São Paulo: Contexto, 2001.

Saudades do futuro: por uma teoria do planejamento territorial do turismo.

São Paulo: Plêiade, 2009. 